\title{
A representação jornalística da Prefeitura Municipal de Santa Maria
}

\section{The journalistic representation of the Santa Maria City Hall}

\author{
Shelli Uílla da Rosa Vidoto ${ }^{[a]}$, Maria Ivete Trevisan Fossá ${ }^{[b]}$, Rejane de Oliveira Pozobon ${ }^{[c]}$ \\ [a] Graduada em Relações Públicas pela Universidade Federal de Santa Maria, Santa Maria, RS - Brasil, e-mail: shellividoto@hotmail.com \\ [b] Doutora em Administração pela Universidade Federal do Rio Grande do Sul e professora adjunta do Departamento de Ciências \\ da Comunicação da Universidade Federal de Santa Maria, Santa Maria, RS - Brasil. \\ [c] Doutora em Ciências da Comunicação pela Universidade do Vale do Rio dos Sinos e professora adjunta do Departamento de \\ Ciências da Comunicação da Universidade Federal de Santa Maria, Santa Maria, RS - Brasil.
}

\section{Resumo}

Este artigo aborda a análise da imagem institucional da Prefeitura Municipal de Santa Maria proposta pela mídia jornalística local. Por meio da avaliação do enquadramento dado às notícias referentes ao órgão, podem-se reconhecer quais os conceitos associados à Prefeitura e qual a imagem institucional que é repassada à sociedade. A pesquisa deu-se por meio da análise de matérias veiculadas em dois jornais da cidade - A Razão e Diário de Santa Maria - durante a primeira semana dos meses de abril a julho de 2010. A fim de que o profissional de Relações Públicas, em sua condição de gestor da comunicação, torne-se conhecedor das possíveis representações que o público possui da organização, objetivou-se esclarecer a imagem institucional de um órgão por meio de suas representações no âmbito jornalístico. Com essa prática, o profissional consegue apreender formas de agendar e contra-agendar a sua organização nos veículos de comunicação.

Palavras-chave: Imagem institucional. Enquadramento. Prefeitura Municipal de Santa Maria.

\section{Abstract}

This article discusses the analysis of the institutional image of the Santa Maria City Hall proposed by local news media. By evaluating the framing of the news regarding the organ, it is possible to recognize the concepts associated with City Hall and what is the corporate image that is passed on to society. The research took place through the analysis of articles published in two newspapers of the city - A Razão and Diário de Santa Maria - during the first week of the months from April to July in 2010. So that the Public Relations professional, in its capacity as manager of 
communication, becomes informed about the possible representations that the public has of the organization, it was aimed to clarify the institutional image of an organ through its offices within the journalistic field. With this practice, the professional can learn ways to schedule and counter-schedule its organization in the media.

Keywords: Institutional image. Framing. Santa Maria City Hall.

\section{Introdução}

No estudo em Relações Públicas, tem-se, como função principal, o relacionamento com os públicos por meio da administração da imagem institucional da organização em que o profissional desse campo atua. Entretanto, a avaliação da imagem institucional de um órgão é, geralmente, desenvolvida com base em parâmetros institucionais, não levando em consideração, por vezes, as imagens propostas por instâncias externas à organização. Deve-se, por exemplo, levar em conta que a mídia é uma instância que influencia as questões debatidas na sociedade e pode interferir na construção das representações das organizações no imaginário do público. Dessa forma, buscou-se articular a função das relações públicas às práticas jornalísticas para compreender como ocorre o processo de enquadramento jornalístico e de que forma este interfere na construção da imagem institucional de um órgão.

Os meios jornalísticos são veículos midiáticos que "pautam para a sociedade os temas de debate e de boa parte das interações do cotidiano (comentários, discussões)" (SILVA, 2007, p. 86). De acordo com essa realidade, pode-se afirmar que esses meios estabelecem os conteúdos que a sociedade determina importantes para contestação, assim como a sociedade também influencia a mídia jornalística na pauta dos assuntos veiculados.

Nesse contexto, exprime-se a ideia de que o acontecimento ${ }^{1}$ exposto na mídia é agendado e enquadrado de acordo com as perspectivas interpretativas, com as quais os veículos de comunicação buscam envolver seus públicos, atrelando conceitos e construindo imagens.
Louis Quéré (2005) exemplifica a gênese dos acontecimentos e atesta a sua relevância, ao exprimir que

há aqueles que ocorrem independentemente da nossa vontade e nos caem em cima contra toda a expectativa e aqueles cuja ocorrência provocamos, (...) controlamos, na maior parte das vezes com objetivos estratégicos. Há aqueles que ocorrem no dia-a-dia, sem que lhes atribuamos um valor particular e aqueles que se revestem de especial importância. Que são mais marcantes, ao ponto de poderem tornar-se referências numa trajetória de vida, individual ou coletiva, na medida em que correspondem a experiências memoráveis e, até mesmo, a rupturas ou a inícios (QUÉRÉ, 2005, p. 59).

De acordo com a perspectiva apresentada por Louis Quéré (2005), afirma-se o acontecimento como instaurador de novas realidades e aplicador de conhecimentos antes não debatidos ou até mesmo pesquisados. Nessa ótica, é importante reconhecer a dimensão significativa que esse fenômeno adquire na realidade de quem, ou do que, lhe está relacionado, e de que maneira essa ocorrência interfere na ordem das coisas.

Nessa dinâmica de ocorrências que emergem, os meios de comunicação exercem a função de selecionar o que se tornará notícia. Assim, a teoria do agenda-setting ou agendamento ${ }^{2}$ determina que os medias exercem poder no processo comunicacional, ao motivar os públicos a dar importância maior aos temas que são expostos nos veículos de comunicação.

1 Rodrigues (1993, p. 27) explica que o acontecimento é tudo aquilo que irrompe na superfície lisa da história entre uma multiplicidade aleatória de fatos. É um acontecimento de natureza especial, distinguindo-se do número indeterminado de acontecimentos possíveis por ser inversamente proporcional à probabilidade de ocorrência; imprevisível.

2 Proposto por Maxwell McCombs e Donald Shaw, no artigo The agenda-setting functions of the mass-media, publicado na revista acadêmica Public Opinion Quarterly. Os autores do agenda setting estruturaram essa hipótese a partir dos estudos de Bernard Cohen e afirmavam que os medias podem não dizer às pessoas como pensar, mas dizem às pessoas no que pensar (SAPERAS, 1993; TRAQUINA, 2004a, b). 
Traquina (2005 apud QUEVEDO; LOOSE, 2009) estabelece que "as notícias ajudam a construir a realidade e, quando a fazem, se utilizam de fórmulas e estratégias para noticiar fatos de grande repercussão, destacando aspectos que são enfatizados".

Para que os acontecimentos tornem-se notícia, Wolf (2002) destaca os requisitos de noticiabilidade para que um fato seja levado ao conhecimento público. Esses atributos são denominados "valores-notícia", tais como: excepcionalidade, sensacionalismo, ausência de ambiguidade, atualidade etc.

Em contrapartida, a sociedade, para poder formar a imagem de uma instituição, usufrui de fontes para ter acesso às informações a respeito da organização em pauta, como o relacionamento da própria instituição com o público, as experiências pelas quais já passou com ela e as notícias veiculadas na mídia. A instância midiática, com relevante representatividade no campo social, tem o poder de influenciar na construção positiva ou negativa da imagem institucional por meio do modo como enquadra as informações referentes às instituições.

Quando o agente jornalístico estabelece um ângulo para expor a informação/acontecimento sobre determinada instituição, ele está enquadrando a realidade de acordo com um ponto de vista. Dessa forma, exprime conceitos que o público tomará como verdadeiros e que influenciarão na formação das representações acerca da organização pela qual se interessa. Entretanto, o enquadramento não se dá apenas pela escolha do "modo de ver" o fato, ou seja, o ângulo em que o acontecimento torna-se mais noticiável na interpretação do público; mas também pela seleção de aspectos que são destacados/priorizados. Essa triagem de elementos (fotos, palavras, expressões) possibilita ao jornalista "tendenciar" o público a interpretar a notícia de acordo com os conceitos/valores/ideologias que pretende repassar no texto.

Nesse sentido, Robert Entman conceitua enquadramento de acordo com os objetivos da fonte (jornalista) e os efeitos sobre o público que recebe as informações: "Enquadrar é selecionar alguns aspectos de uma realidade percebida e fazê-los mais salientes em um texto comunicativo, de maneira a promover uma definição particular do problema, interpretações causais, avaliações morais e/ou recomendações de tratamento para o item descrito" (ENTMAN, 1993, p. 52).
Os medias, pois, instauram critérios de apresentação das notícias, por meio dos enquadramentos utilizados, para constituírem um "mundo de significados" (GOFFMAN, 1974) correlacionados aos parâmetros sociais e culturais de uma época, de um local, de uma sociedade. Com essa prática, determinam o que as pessoas podem pensar sobre fatos, pessoas e instituições.

A Prefeitura Municipal de Santa Maria é a instituição pública que possui o poder sobre as questões políticas, econômicas e sociais da cidade, e, por isso, as informações em torno de suas ações e decisões são muito visadas pela população santa-mariense. De acordo com esse contexto, as informações referentes à Administração Municipal da cidade de Santa Maria são pauta frequente nos veículos de comunicação local e a forma como elas são enquadradas no meio jornalístico pode interferir positiva ou negativamente na imagem da referida instituição.

Entendendo-se o processo de construção da imagem institucional, por meio das considerações de Almeida (2009b, p. 228), como o "somatório de sensações, percepções e inter-relações de atores sociais", destaca-se a capacidade da mídia de influenciar o público leitor na apropriação de sentidos a respeito da instituição analisada. Com isso, os valores e os sentidos a que a Prefeitura Municipal é relacionada nas matérias promoverão o conhecimento da imagem institucional dessa proposta pela instância midiática.

\section{Materiais e métodos}

A fim de estudar o enquadramento jornalístico que os veículos $A$ Rąão e Diário de Santa Maria dão às informações referentes à Prefeitura Municipal e a sua interferência na formação da imagem institucional daquele órgão público, analisaram-se as matérias veiculadas na primeira semana dos meses entre abril e julho de 2010, nos jornais impressos citados. O corpus de pesquisa foi examinado por meio da análise de conteúdo (AC), a qual possibilitou o estudo exploratório e descritivo das mensagens inseridas nas matérias analisadas.

Para Herscovitz (2007, p. 128), análise de conteúdo é o "método centrado em codificações e definições operacionais individuais, porém replicáveis, que buscam desvendar as pistas de textos, 
símbolos, sons e imagens". De acordo com o autor, o método, que possui fundamentos para análise quantitativa e qualitativa, pode ser empregado em pesquisas exploratórias, descritivas e explanatórias, pois se usa categorias previamente testadas, exclusivas e passíveis de replicação, o que corrobora a capacidade de suporte de conceitos mensurados quantitativa e qualitativamente.

Tomando como base conceitos positivistas $^{3}$ de Augusto Comte (1798-1857), os estudiosos defendiam a dimensão quantitativa do método, dos quais "as características sintáticas e semânticas, os símbolos, os tamanhos e formatos deveriam ser computados matematicamente" (HERSCOVITZ, 2007, p. 124).

As discussões sobre a eficiência, a aplicabilidade e a eficácia da análise de conteúdo estimularam a renovação constante do método, principalmente com relação às técnicas de captação das informações (auxílio do computador) e de sua mensuração (quantitativa e qualitativamente). Em 1955, pesquisadores de diversas áreas demonstravam grande interesse pelo método, que estava incorporando novas contribuições à pesquisa. Nesse mesmo período, a ênfase no aspecto quantitativo da $\mathrm{AC}$ foi superada graças à consciência de que essa metodologia não objetivava um resultado descritivo, mas que sua função era a inferência ${ }^{4}$.

Com a flexibilidade das funções da AC e a utilização de técnicas que fornecem o alcance de resultados quantitativos e qualitativos em pesquisa, a tendência para a metodologia é oscilar entre esses dois polos de resultados, dependendo dos interesses do pesquisador. Nesse sentido, é relevante que as etapas percorridas, na pesquisa, forneçam subsídios para que o resultado, que é esperado pelo pesquisador, possa ser alcançado. Dessa forma, a análise de conteúdo é estruturada por três etapas, fomentando as necessidades de análise tanto quantitativa, como qualitativa: pré-análise, exploração do material e interpretação. ${ }^{5}$
O processo de leitura flutuante do objeto de estudo promoveu, além da contagem quantitativa dos dados, o conhecimento do corpus e a possibilidade de uma pré-análise, na qual foram assentadas as considerações a respeito do conteúdo latente dos textos. O rastreamento das categorias de análise foi a base para a averiguação dos valores e dos sentidos relacionados à Prefeitura Municipal de Santa Maria e da estruturação da imagem proposta pela mídia local.

Para estudar a construção da imagem da Prefeitura Municipal de Santa Maria, foi considerado apenas o seu caráter institucional. Desse modo, a análise do corpus selecionado não levou em consideração as questões políticas que permeiam a instituição, o que poderia influenciar na avaliação dos valores-notícia reconhecidos.

\section{Resultados}

Com o estabelecimento de categorias, pode-se constatar como a Prefeitura Municipal é apresentada pela mídia impressa local.

Por meio da análise de trechos (parágrafos ou frases) das notícias, o conteúdo exposto pelos veículos de comunicação coloca a instituição analisada como instância de decisão, visibilidade, envolvimento ou desinteresse. Dentro desse contexto, tais categorias, respectivamente, reuniram acontecimentos em que a Prefeitura era protagonista de eventos burocráticos para viabilizar ações de melhoria na cidade; da participação e do desenvolvimento de atividades para o possível agendamento na mídia; da implementação de estratégias que auxiliavam na saúde, educação, transporte, cultura e lazer; e de ocorrências em que a sua atuação era desacreditada.

Entre as 232 notícias destacadas dos jornais $A$ Razão e Diário de Santa Maria, 91 possuíam fotos; 34 tinham chamadas na capa - das quais, 11 traziam fotos; para seis foram dadas chamadas na

\footnotetext{
3 Sua principal característica é a valorização das ciências exatas como paradigma de cientificidade. Na visão positivista, até mesmo as teorias sobre vida social "deveriam ser formuladas de forma rígida, linear e metódica, sobre uma base de dados verificáveis" (JOHNSON, 1997, p. 179 apud FONSECA JÚNIOR, 2010, p. 281).

4 De acordo com Duarte e Barros (2010), a inferência pode ser explicada como a dedução lógica de conhecimentos sobre o emissor ou destinatário da comunicação, por meio da análise de elementos latentes de um texto, imagem, mensagem. Com o foco nos mecanismos subjacentes do objeto estudado, a inferência contribui para amenizar o impacto quantitativo da análise de conteúdo. 5 Proposta de Laurence Bardin (1988 apud FONSECA JÚNIOR, 2010).
} 
contracapa - em que três foram anexadas fotos; e três possuíam infográficos.

Do total de matérias selecionadas para o corpus, foram contabilizadas 117 notícias no Diário de Santa Maria (DSM) e 115 no Jornal A Razão. No primeiro, considerando-se o número de matérias por seções, a editoria que mais apresentou notícias a respeito da Prefeitura foi a Geral, com 37 matérias - incluindo notas. As demais editorias também trouxeram significativo montante de notícias, exceto os cadernos de finais de semana ou editorias especiais. Dessa maneira, as matérias da Prefeitura, nas demais editorias do DSM, expressaram-se assim: economia - 17 matérias; página 2 - 16; política - 15; opinião - 10; aparte - seis; Caderno Diário 2 - seis; Dia a dia - três; polícia - duas; esportes - uma; diário da região - uma; revista mix - uma; na cidade - uma; especial - uma.

No jornal $A$ Razão, a editoria Geral também englobou o maior número de notícias da Prefeitura comparado ao restante das editorias e dos cadernos. Assim, a divisão de matérias por editoria desse veículo deu-se da seguinte forma: Geral - 37 matérias; resumo - 23; política - 13; economia - 11; serviço - 11; contracapa - nove; espaço do leitor - quatro; Segundo A Razão - três; esportes - duas; A Razão de Ler - uma; A Razão Cursos e Concursos - uma.

$\mathrm{Na}$ categoria que intitula a Prefeitura Municipal como instância de decisão, 58 notícias foram contadas, sendo que o jornal Diário de Santa Maria agendou 34 matérias com tal temática e, em A Razão, foram classificadas 25 notícias que seguem esta tipologia. Já para a segunda categoria que considera a Prefeitura como instância de visibilidade, 15 notícias foram verificadas. Entre estas, cinco matérias foram produzidas pelo jornal DSM e 10, pelo jornal $A$ Razão. Na terceira categoria de análise das matérias, a Prefeitura revela-se como instância de envolvimento em 91 notícias, das quais 44 o DSM publicou e 46 foram escritas pelo jornal $A$ Razão. Na categoria em que a instituição analisada é classificada como instância de desinteresse, 28 notícias são encontradas, das quais 15 pertencem ao Diário de Santa Maria e 13, ao A Razão.

Considerando-se a Prefeitura Municipal de Santa Maria como o órgão que possui a função de administrar a cidade e tem o poder de estabelecer a ordem sobre a comunidade, foi quase instantânea a constatação de suas aparições nos textos jornalísticos como instância de decisão. Tal posicionamento a que as matérias referem-se está ligado à atuação da Prefeitura na aprovação de projetos, assinatura de documentos, abertura de licitações, estabelecimento de prazos, chamada de profissionais e estagiários etc.

Sob a luz dessa categoria, o jornal Diário de Santa Maria agendou e enquadrou matérias em que o poder de decisão da Prefeitura refletia em sua imagem aspectos que simbolizavam o seu domínio sobre assuntos específicos. De acordo com Pefeffer (1977 apud ALMEIDA 2009a, p. 229), Treadwell e Harrison (1994 apud ALMEIDA 2009a, p. 229), "a imagem informa sobre as características de uma organização". Nesse sentido, a função reguladora que a Prefeitura possui na cidade é apresentada na mídia e auxilia na construção de uma imagem que a relaciona a aspectos dessa natureza.

Como a instituição possui inúmeros setores e secretarias, em grande parte das notícias selecionadas para o corpus, a Prefeitura aparece "representada" por alguma pessoa ou órgão ligado a ela, caracterizando o agendamento de atributos, como no trecho que segue:

a prefeitura informou que fez a vistoria nos 55 ônibus novos da frota de Santa Maria, que já vêm com a catraca na frente e elevador para cadeirantes. [...] De acordo com o secretário de Controle e Mobilidade Urbana, Sérgio Medeiros, as mudanças serão fiscalizadas nas vistorias que a prefeitura faz anualmente na frota (MALLMANN, 2010).

Considerando-se que o agendamento de atributos "é a seleção - e ênfase - nos atributos particulares de uma agenda da mídia" (MCCOMBS, 2009, p. 137), nesse caso, enfocou-se o chefe de uma secretaria - seção/parte da estrutura organizacional da Prefeitura, atentando para a fonte de informação da qual se obteve as informações. O texto enquadra a função decisória da Prefeitura no que concerne ao transporte público santa-mariense, porém, ressalta um elemento (o secretário) a fim de que este seja notável ao público como o responsável pela decisão estabelecida.

Existem, também, ocasiões em que o responsável por toda a instituição - o prefeito - é destacado; representando a Prefeitura nos atos decisórios: 
o prefeito buscará substitutos para os secretários Tubias Calil, Jorge Pozzobom e Cézar Busatto. [...] Schirmer estaria estudando outras mudanças. Uma delas seria a criação da Secretaria de Governo, encarregada de cuidar da relação política com a comunidade e também da comunicação do governo (SILVEIRA, 2010).

Com realce nas mudanças da estrutura pessoal e organizacional a que o Prefeito foi encarregado, o jornal Diário de Santa Maria associa a imagem da Prefeitura a de um indivíduo, estimulando a apreensão de sentidos por meio da ênfase de um artifício.

Além do sentido de poder, as matérias trazem o agendamento de atributos com o objetivo de tornar mais humanas e próximas da comunidade as ações da Prefeitura: "A decisão já foi tomada pelo Prefeito Cezar Schirmer: 117 agentes comunitários de saúde, aprovados no concurso de 2008, serão chamados nos próximos dias. Eles vão atuar no Estratégia de Saúde da Família (ESF)" (ROESE, 2010).

Esse procedimento propicia à organização "uma impressão pública que atrai o público de seu interesse" (ALMEIDA, 2009b, p. 228), uma vez que está relacionada a ações desenvolvidas em prol da comunidade.

O jornal $A$ Razão também agendou matérias e notas que apresentavam a Prefeitura sob a ótica de instância de decisão.

Em consonância com a veiculação de informações que vão da Prefeitura à comunidade, também foram publicadas mensagens que objetivavam salientar a preocupação da prefeitura com as solicitações dos santa-marienses:

em resposta ao leitor Cláudio Junior, em carta publicada no final de semana (primeiro e dois de maio) No Espaço do Leitor (p. 2), a secretaria de Proteção Ambiental esclarece que tomará as medidas cabíveis em relação a solicitação de corte de uma árvore em via pública. O referido pedido do cidadão [...] já tem a autorização da secretaria para ser efetuado (Jornal A Razão, 6 de maio de 2010, Espaço do Leitor).

Dessa forma, pode-se constatar, a partir das ponderações de Almeida (2009b, p. 274), que “a percepção que as pessoas têm sobre a organização pode influir em suas decisões", ao passo que as iniciativas do órgão são reguladas, em certas circunstâncias, pelos processos requeridos pela comunidade.

$\mathrm{O}$ jornal $A$ Razão agendou, além disso, matérias no Espaço do Leitor que tratavam sobre a Prefeitura e os procedimentos de decisão por ela empregados. No dia 2 de julho de 2010, foi veiculada a nota - trecho que segue -, em que uma ação empreendida pelo Prefeito de Santa Maria é elogiada por um cidadão: "Parabéns! Sr. Prefeito Cezar Schirmer, finalmente, a Avenida Rio Branco prepara-se para retornar à beleza que caracterizava. [...] Parabéns! Pela habilidade e firmeza com que conduziu essa empreitada, conseguindo que os comerciantes informais, abandonassem pacificamente os espaços que ocupavam". Sob à luz desse acontecimento, esse apoio comunitário à atuação da Prefeitura, por meio da mídia, estimula o agendamento de informações subsequentes ao assunto em pauta, abordando enquadramentos diferenciados e intensificando a divulgação de notícias relevantes à imagem institucional do órgão.

O reconhecimento da Prefeitura Municipal de Santa Maria como instância de decisão nos textos midiáticos esclarece as estratégias de veiculação que os jornais diários colocam sobre os assuntos pautados. Além de agendar o órgão como o principal responsável pelos processos decisórios que acontecem na cidade, a relação dele com os cidadãos e as formas como as decisões são apreendidas pela comunidade também são ressaltadas, contribuindo para a compreensão de sentidos, valores e imagens associadas à instituição.

A administração municipal, ademais, foi enquadrada pelos veículos de comunicação como a instância responsável pela promoção de ações que objetivavam a melhoria das condições de vida da comunidade santa-mariense por meio da saúde, educação, transporte, bem como o apoio a projetos culturais, esportivos e sociais. Em face disso, averiguou-se a presença da Prefeitura Municipal nas matérias dos jornais A Razão e Diário de Santa Maria como instância de envolvimento. De acordo com Balmer (1998 apud ALMEIDA, 2009b, p. 232), "a imagem [...] está relacionada às opiniões mais recentes do público acerca de uma organização”. Assim, o que os meios veiculam a respeito de uma instituição reflete no imaginário dos indivíduos interessados nas ações empreendidas. 
Uma ação de melhoramento da saúde pública santa-mariense é focalizada pelo jornal Diário de Santa Maria, apresentando a Prefeitura de forma favorável à sua imagem:

depois de ser colocado em prática, o novo sistema de coleta seletiva promete mudar a vida de muitos catadores. Isso porque todo o material recolhido pelos caminhões será destinado às cooperativas de reciclagem licenciadas e cadastradas na prefeitura. [...] - A ideia é que mais catadores se associem às cooperativas existentes e que novas sejam criadas, gerando trabalho e renda - projeta o secretário de Proteção Ambiental, Luiz Alberto Carvalho Júnior (COOPERATIVAS, 2010).

A ocorrência de maus tratos a animais de grande porte em Santa Maria foi o motivo do agendamento da nota que segue: "A Secretaria de Proteção Ambiental se reuniu ontem com outros órgãos para tratar da questão dos animais abandonados em Santa Maria. Definiu-se no encontro que [...] será apresentado um projeto de um centro de zoonoses" (CENTRO, 2010).

Considerando o enquadramento da reunião entre membros da secretaria responsável por assuntos ambientais da Prefeitura e outros órgãos interessados, o veículo articulou as informações de modo que a instituição analisada pudesse ser associada a valores, sentidos e significações favoráveis ao zelo e à integridade dos animais. Com isso, a imagem é diretamente ligada a aspectos positivos, já que a preocupação com o meio ambiente e a atenção ao bem-estar dos animais é o diferencial das organizações do mundo atual.

A Prefeitura Municipal de Santa Maria foi agendada como instância de envolvimento nas edições do jornal $A$ Razão. Em conformidade com as matérias veiculadas no Diário de Santa Maria, os textos cabíveis nessa categoria apresentavam a instituição relacionada a valores e significações favoráveis a sua imagem.

Tomando como referência o envolvimento da Prefeitura aos temas esporte, educação e lazer, o jornal $A$ Razão agendou eventos em que a instituição era parceira na sua promoção ou apoiava-os de forma significativa. Com isso, o agendamento de informações, nesse aspecto, está exemplificado pelos trechos que seguem: "a competição tem o apoio da prefeitura municipal, através da secretaria de esporte, lazer, juventude, idoso e criança. [...] 'Recebemos um grande incentivo da prefeitura, sem falar na estrutura do clube, como as quadras de saibro em bom estado' elogiou André Bueno, da Oxy Sport's, organizadora do evento" (Jornal A Razão, 3 e 4 de abril de 2010, editoria Esporte).

Nesse fragmento, ao ser agendada a participação da Prefeitura no $3^{\circ}$ Santa Maria Open e na Copa Docelina de Tênis no ATC, é salientada, por meio do enquadramento da fonte, a relevância que a instituição dá a eventos dessa natureza, corroborando o seu envolvimento com atividades de cunho social.

Com enfoque em ações que têm o intuito de promover melhorias na educação de crianças, jovens e adultos, o trecho, a seguir, exemplifica as ações da Prefeitura no que tange a esse aspecto:

o prefeito Cezar Schirmer visitou a escola de Educação Infantil Casa da Criança, e as Escolas de Ensino Fundamental Duque de Caxias, Castro Alves, Tenente João Pedro Mena Barreto e Fontoura Ilha. O objetivo das visitas, que acontecem com a presença do secretário de Educação, João Luiz Roth, é identificar as necessidades das escolas, conhecer os professores e conversar com os alunos. Também faz parte do esforço do governo municipal valorizar e qualificara educação pública (Jornal A Razão, 3 e 4 de julho de 2010, Geral).

Tendo como ponto de partida que a ação desenvolvida pela Prefeitura busca uma maior proximidade entre comunidade, escola e a administração municipal, o enquadramento dado à notícia não poderia ser diferente. $\mathrm{O}$ envolvimento do Prefeito com a educação do município é apresentada de forma clara e positiva na matéria referida, o que contribui para uma imagem institucional afirmativa do órgão.

Um aspecto que pode prejudicar a imagem institucional da Prefeitura Municipalé o descaso com cidadãos, comunidades ou instituições que atendam aos indivíduos carentes. Ocorrências dessa dimensão são, geralmente, agendadas pelos veículos de comunicação sendo seguidas por depoimentos das pessoas que pedem pela resolução de tais problemas. Devido a esses eventos, outra categoria de análise 
foi detectada, em que se coloca a Prefeitura como instância de desinteresse.

Em algumas de suas edições, o jornal Diário de Santa Maria enquadrou matérias que se adequam na categoria em questão e esclarecem à comunidade santa-mariense o estabelecimento de prioridades em detrimento das demais demandas. O trecho a seguir enquadra a reclamação de um morador do distrito de Colônia Pinheiro, que atribui o mau estado da estrada à falta de interesse da Prefeitura em melhorar o trecho: "Esse problema não é de hoje. Se eles (prefeitura) patrolassem a cada dois, três meses. Mas não, estamos esquecidos - diz Fabiano Dutra" (CHARÃO, 2010). Com esse enfoque negativo, a Prefeitura perde credibilidade perante os públicos, sendo entendida como um órgão displicente e aquém das necessidades requeridas pela população.

Outro aspecto abordado pelo DSM é a apresentação da Prefeitura como negligente no campo da saúde. O enquadramento da instituição como instância de desinteresse é exemplificado com o trecho da editoria Página 2, do dia 7 de abril de 2010; o desabafo de Joacyr Dias, publicitário, sobre as instalações precárias da unidade de saúde do bairro Tancredo Neves, leva a população ao questionamento das reais prioridades da administração municipal: "Afinal, saúde é prioridade ou não é?".

Dentro desse contexto, o jornal $A$ Razão também enquadrou matérias que focalizavam a Prefeitura Municipal como instância de desinteresse. O agendamento de notícias que enfocam a displicência da Prefeitura com relação ao espaço público - ruas, vias, lugares - segue no fragmento:

o clamor é de moradores deste trecho da rua que dizem estar esquecidos pela Prefeitura. "O abandono é total. No terminal de ônibus UFSM, por exemplo, é um lixo só. É comum ver os fiscais dos ônibus pegarem a vassoura. Há muito tempo não se vê as equipes de varrição da Prefeitura cruzar por aqui", protestou uma das moradoras. Prefeitura: ninguém da secretaria de Infraestrutura, Habitação e Serviços do Município foi localizado para falar sobre a reclamação dos moradores (Jornal A Razão, $1^{\circ}$ de abril de 2010, Economia).

Nesse sentido, a atuação da Prefeitura é ligada a conceitos como abandono e esquecimento.
As questões de saúde pública, segurança e higiene também são afetadas pelo agendamento de notícias que assinalam a fraca atuação da Prefeitura com relação a tais temáticas. No trecho a seguir, pode-se entender como este aspecto é abordado:

só pelo conserto do vazamento, já foram encaminhados pelo menos uns três pedidos junto à secretaria responsável do município, mas até agora nada - lamentou o presidente da Associação comunitária do bairro São José, Batista Comoreto. Sobre o buraco [...] é sempre um risco para quem usa a via, tanto pedestres como motoristas, preocupa-se (Jornal A Razão, 2 de junho de 2010, Serviço).

O trecho salientado deixa clara a posição da Prefeitura em ignorar as solicitações dos cidadãos. Vê-se que a associação de valores como desleixo, abandono, carência eincompetência à Prefeitura Municipal de Santa Maria estabelece uma imagem de negligência quanto aos seus deveres com a comunidade santa-mariense; contribuindo para interpretações desfavoráveis na percepção de seus públicos.

$\mathrm{O}$ agendamento de informações sobre a Prefeitura dá-se naturalmente pela representação que o órgão possui na comunidade santa-mariense. Contudo, na busca pelo estreitamento de relações e a passagem de percepções favoráveis quanto à instituição, esta desenvolve ações em que a visibilidade tem a função de divulgá-la, emergindo a categoria que a coloca como instância de visibilidade.

Considerando que visibilidade, de acordo com Thompson (2008), é o estado de estar visível na imprensa, no meio eletrônico ou com auxílio de qualquer outro instrumento de mídia, o intuito da Prefeitura em promover a sua visibilidade é estimular a agenda midiática sobre suas ações. Chaparro (2006) complementa essa hipótese ao afirmar que

[...] noticiar se tornou a mais eficaz forma de agir no mundo e com ele interagir; as relações com a imprensa passaram a constituir preocupação prioritária na estratégia das instituições, tanto as empresariais quanto as governamentais, para as interações com a sociedade - à qual se ligam, hoje, mais por teias comunicativas do que por atividades ou ações de materialidade objetiva (CHAPARRO, 2006 apud SARTOR, 2009, p. 3). 
Mesmo tratando de assuntos delicados, o jornal Diário de Santa Maria enquadrou as estratégias de visibilidade empreendidas pela Prefeitura. No fragmento que segue, o depoimento do Prefeito esclarece a importância da visibilidade para a agregação de valores e o estímulo ao relacionamento com os públicos de interesse: "Aliviado com a transferência tranquila, Schirmer dizque, do ponto de vista do simbolismo, essa éuma das ações de maior visibilidade de sua gestão. Sem dúvida, o governo marcou pontos na delicada tarefa" (Diário de Santa Maria, 3 e 4 de julho de 2010, editoria Aparte). A transferência dos camelôs, artesãos eambulantes para o Shopping Independência possibilitou o agendamento de inúmeras notícias a respeito da Prefeitura e de suas ações, além de propiciar à instituição a oportunidade de associar a sua imagem a eventos de caráter social.

O jornal $A$ Razão também enquadrou pautas que apresentavam a Prefeitura Municipal como instância de visibilidade, exemplificando o modo como tais informações são apresentadas na mídia e que efeitos causaram na imagem institucional do órgão.

Um evento religioso, por exemplo, contou com a participação da figura do prefeito, o que deu visibilidade à Prefeitura em duas edições do jornal: “A Ordem dos Ministros Evangélicos de Santa Maria [...] promove neste sábado um evento dedicado a todas as religiões de Santa Maria. [...] O prefeito Cezar Schirmer também confirmou presença" (1 e 2 de maio de 2010, editoria Geral). "O Prefeito saudou os fiéis e enalteceu a iniciativa, que além de ser uma reafirmação de fé e de união entre as pessoas, este ano aborda um tema de extrema importância, que é o problema das drogas na sociedade e como as famílias devem agir para combater este drama dentro de seus lares" (3 de maio de 2010, editoria Resumo). Ambas as matérias envolveram a imagem da Prefeitura com valores ligados à fé e à união, propiciando o maior engajamento de fiéis às ações desta.

Sob esse contexto, o enquadramento jornalístico dado às informações interfere diretamente na apresentação da Prefeitura Municipal na imprensa, atribuindo valores e novas significações às suas ações perante os públicos de interesse.

\section{Considerações finais}

Considerando-se o campo das Relações Públicas, a importância de conhecer o modo como uma instituição é apresentada na mídia revela-se interessante no que concerne ao conhecimento e à avaliação das significações que lhe são associadas. Com o objetivo de averiguar de que forma as informações de uma instituição podem ser agendadas e como os enquadramentos jornalísticos interferem na apresentação da imagem institucional de uma organização, essa pesquisa buscou reconhecer os valores e/ou sentidos associados à Prefeitura Municipal de Santa Maria e como estes poderiam contribuir para a formação da sua imagem institucional.

Foi possível averiguar quatro categorias de análise que colocavam a Prefeitura Municipal de Santa Maria como instância de decisão, envolvimento, desinteresse e visibilidade, as quais nortearam o estudo das matérias. Como instância de decisão, as matérias geralmente enfocavam as funções administrativas desempenhadas pelo órgão e fizeram imperar o comprometimento institucional com o andamento dos projetos da cidade. A categoria que enquadrou o órgão como instância de envolvimento deu foco ao desenvolvimento de melhorias para a cidade e para o bem-estar dos cidadãos, propiciando uma imagem institucional favorável à Prefeitura.

Quando posta como instância de desinteresse, a Prefeitura despertou, na agenda midiática, valores prejudiciais a sua imagem institucional. Considerou-se, portanto, a fraca atuação em diversos segmentos da sociedade no que concerne à resolução de problemas e ao cumprimento de acordos. Quando categorizada como instância de visibilidade, a Prefeitura estava comprometida com o apoio a atividades/eventos culturais, ambientais, esportivos e sociais.

A análise das matérias que foram veiculadas nos jornais A Raqão e Diário de Santa Maria possibilitou a segmentação das representações daquele órgão público por meio das categorias estabelecidas. Em face do exposto, os objetivos propostos pela pesquisa foram alcançados, pois foram averiguados os valores associados à instituição e às imagens institucionais propostas pela mídia impressa.

\section{Referências}

ALMEIDA, A. L. de C. Identidade, imagem e reputação organizacional: conceitos e dimensões da práxis. In: KUNSCH, M. M. K. (Org.). Comunicação organizacional: linguagem, gestão e perspectivas. São Paulo: Saraiva, 2009a. v. 2. 
ALMEIDA, A. L. de C. Pressupostos teórico-metodológicos para o estudo da identidade e da reputação organizacional. In: KUNSCH, M. M. K. Relações públicas: história, teorias e estratégias nas organizações contemporâneas. São Paulo: Saraiva, 2009b. p. 263-289.

CHARÃO, L. É difícil ir até Colônia Pinheiro. Diário de Santa Maria, Santa Maria, n. 2463, 5 abril 2010. Disponível em: <http://www.clicrbs.com.br/dsm/rs/impressa/4,38,2861723,14431>. Acesso em: 6 abril 2010.

COOPERATIVAS serão criadas para catadores. Diário de Santa Maria, Santa Maria, n. 2516, 3 jun. 2010. Disponível em: <http://www.clicrbs.com.br/dsm/rs/impressa/4,38,2924449,14819>. Acesso em: 5 jun. 2010.

CENTRO de zoonoses. Diário de Santa Maria, Santa Maria, n. 2461, 2 abril 2010. Disponível em: < http:/ / www. clicrbs.com.br/dsm/rs/impressa/4,38,2859309,14417>. Acesso em: 6 abril 2010.

ENTMAN, R. M. Framing: toward clarification of a fractured paradigm. Journal of Communication, v. 43 , n. 4 , p. $51-58,1993$.

FONSECA JÚNIOR, W. C. da. Análise de conteúdo. In: DUARTE, J.; BARROS, A. (Org.). Métodos e técnicas de pesquisa em comunicação. São Paulo: Atlas, 2010.

GOFFMAN, E. Frame analysis: an essay on the organization of experience. London: Harper and Row, 1974.

HERSCOVITZ, H. G. Análise de conteúdo em jornalismo. In: LAGO, C.; BENETTI, M. Metodologia de pesquisa em jornalismo. Petrópolis: Vozes, 2007.

MALLMANN, F. Os prós e os contras do sim. Diário de Santa Maria, Santa Maria, n. 2461, 2 abril 2010. Disponível em: <http://www.clicrbs.com.br/dsm/rs/impressa/4,40,2859279,14417>. Acesso em: 5 abril 2010.

MCCOMBS, M. A teoria da agenda: a mídia e a opinião pública. Petrópolis: Vozes, 2009.

QUÉRÉ, L. Entre o facto e sentido: a dualidade do acontecimento. Trajectos, Revista de Comunicação, Cultura e Educação, n. 6, p. 59-75, 2005.

QUEVEDO, J. P.; LOOSE, E. B. Enquadramentos da tragédia de Santa Catarina em Veja e Epoca. Contemporânea, v. 2, n. 13, p. 80-94, 2009.

RODRIGUES, A. D. O acontecimento. In: TRAQUINA, N. (Org.). Jornalismo: questões, teorias e "estórias". Lisboa: Vega, 1993.
ROESE, L. 117 agentes de saúde serão chamados. Diário de Santa Maria, Santa Maria, n. 2492, 7 maio. Disponível em: <http://www.clicrbs.com.br/dsm/rs/ impressa/4,38,2896259,14647>. Acesso em: 10 maio 2010.

SAPERAS, E. Os efeitos cognitivos da comunicação de massas: as recentes investigações em torno dos efeitos da comunicação de massas: 1970/1986. Porto: Asa, 1993.

SARTOR, B. A. Assessoria de imprensa e visibilidade: a imagem-conceito das organizações no incontrolável domínio da notícia. In: CONGRESSO BRASILEIRO CIENTÍFICO DE COMUNICAÇÃO ORGANIZACIONAL E RELAÇÕES PÚBLICAS, 3., 2009, São Paulo. Anais... São Paulo: GT Abrapcorp 2, 2009.

SILVA, L. M. da. Sociedade esfera pública e agendamento. In: LAGO, C.; BENET'TI, M. Metodologia de pesquisa em jornalismo. Petrópolis: Vozes, 2007.

SILVEIRA, J. Virada de mesa no meio político. Diário de Santa Maria, Santa Maria, n. 2460, 1 abril 2010. Disponível em: <http://www.clicrbs.com.br/dsm/rs/impressa/4,43,2858005,14407>. Acesso em: 5 abril 2010.

TRAQUINA, N. Teorias do jornalismo: porque as notícias são como são. Florianópolis: Insular, 2004a.

TRAQUINA, N. A tribo jornalística: uma comunidade transnacional. Lisboa: Editorial Notícias, 2004b.

THOMPSON, J. B. A nova visibilidade. Matrizes, v. 1, n. 2, p. 15-38, 2008.

WOLF, M. Teorias da comunicação. 7. ed. Lisboa: Presença, 2002.

Recebido: 11/04/2011

Received: 04/11/2011

Aprovado: 26/10/2011

Approved: 10/26/2011 